\title{
Porcine circovirus type 2 (PCV2)-infection and re-inoculation with homologous or heterologous strains: virological, serological, pathological and clinical effects in growing pigs
}

\author{
Tanja Opriessnig ${ }^{1 *}$, John R. Prickett ${ }^{1}$, Darin M. MAdson ${ }^{1}$, Hui-Gang Shen ${ }^{1}$, \\ Nicole M. Juhan ${ }^{2}$, Roman M. PogranichniY ${ }^{3}$, Xiang-Jin Meng ${ }^{2}$, \\ Patrick G. HALBUR ${ }^{1}$ \\ ${ }^{1}$ Department of Veterinary Diagnostic and Production Animal Medicine, College of Veterinary Medicine, \\ Iowa State University, Ames, Iowa 50011, USA \\ ${ }^{2}$ Department of Biomedical Sciences and Pathobiology, Center for Molecular Medicine and Infectious Diseases, \\ College of Veterinary Medicine, Virginia Polytechnic Institute and State University, Blacksburg, Virginia, USA \\ ${ }^{3}$ Department of Comparative Pathobiology, Purdue University, West Lafayette, Indiana, USA
}

(Received 10 September 2009; accepted 13 January 2010)

\begin{abstract}
Long-term PCV2 infection and/or concurrent infection with genotypes PCV2a and PCV2b may play a role in the development of clinical porcine circovirus-associated disease (PCVAD). To evaluate this premise, 24 11-week-old specific pathogen-free (SPF) pigs were randomly assigned to 1 of 4 treatments: negative controls, a single inoculation with PCV2a, single inoculation followed by re-inoculation with a homologous PCV2a strain, or repeated inoculations with heterologous strains (PCV2a, PCV2b). Pigs were evaluated for clinical signs daily through 140 days post inoculation (dpi). Serum samples were collected every other day from dpi 0 through 14 and weekly thereafter. PCV2-inoculated pigs were viremic by dpi 2 and 13 of 18 pigs remained viremic at $140 \mathrm{dpi}$. No statistical differences in the onset, level, or duration of PCV2 viremia were detected among treatment groups. Anti-PCV2 antibodies were detected between 14 and $28 \mathrm{dpi}$ and were present through $140 \mathrm{dpi}$ without statistical differences in antibody response among treatment groups. In the current study, pigs had extended viremia combined with detectable tissue PCV2 antigen levels despite the presence of high levels of anti-PCV2 antibody; however, no clinical disease was observed.
\end{abstract}

PCV2 / heterologous challenge / persistence / viremia / serological response

\section{INTRODUCTION}

Porcine circovirus type 2 (PCV2) is a small, single-stranded, circular DNA virus [45] associated with respiratory, enteric, reproductive and systemic disease [1]. To date, there are three

\footnotetext{
* Corresponding author: tanjaopr@iastate.edu
}

known genotypes of PCV2. PCV2a was reported in archived porcine tissue samples from northern Germany in 1962 [20] and antiPCV2 antibodies were detected as early as 1985 in the North America [27]. PCV2b was reported in 2005 in North America and with increasing frequency thereafter [7, 8, 18]. PCV2c was recently reported in Denmark from archived serum samples from non-clinical 
pigs in 1980, 1987 and 1990 [9]. PCV2c isolates are more closely related to PCV2b (95\%) than PCV2a (91-93.6\%) in sequence homology [9].

The majority of experimental inoculation studies have focused on characterizing the infectivity and virulence of PCV2a isolates. Experimental infection of colostrum-deprived pigs demonstrated shedding of PCV2a DNA in feces, nasal, oropharyngeal and tonsillar secretions as early as one day post inoculation (dpi) [2, 6, 43]. Viremia, nasal, oropharyngeal, and fecal shedding of PCV2a DNA has been reported to persist at least 70 days in colostrum-deprived pigs [43]. Characteristic lesions (i.e. lymphocyte depletion and histiocytic replacement within lymphoid tissues) appear by 7 days post-infection and persist for variable amounts of time [17]. Experimental infection of conventional, specific-pathogen-free (SPF) pigs has been shown to result in viremia by $2 \mathrm{dpi}$ and a detectable anti-PCV2 IgG response by 13 days post-infection [25]. Characteristic histological lesions were observed at 7 days postinfection in SPF pigs [47]. Several case-control studies have provided cross-sectional data throughout the pig production cycle on viremia and the serological response following natural PCV2 infection in conventional swine herds. These studies indicated that viremic animals are commonly present in herds without clinical signs at 11 weeks of age [24]. In herds with clinical signs, viremic animals were present earlier (7 weeks) [24] and, in most cases, the amount of virus present was higher in clinically affected pigs [5].

While the above-described studies focused on viremia and seroconversion following PCV2a infection, few have described experimental PCV2b infection and even fewer have attempted to assess the interactions between strains of PCV2a and PCV2b. In one such study, pigs were infected with PCV2a or PCV $2 b$ and re-infected 35 days later with a heterologous strain [38]. All pigs were necropsied 56 days after the initial inoculation. Increased levels of PCV2 DNA or anti-PCV2 antibody were not observed in pigs dually infected with PCV2a and PCV2b [38]. In a case-control study [46], an association of porcine dermatitis and nephropathy syndrome (PDNS) and high levels of anti-PCV2 antibodies was described. The authors observed that numbers of CD8+ cells were increased in renal tissues and hypothesized that cytotoxic cells may be involved in the pathogenesis of PDNS [46].

Most herds in North America are infected with both PCV2a and PCV2b and the viruses are likely endemic in most swine populations ${ }^{1}$. Therefore, understanding the interactions between PCV2a and PCV2b and their effect on viremia, seroconversion, and the development of clinical disease is important for developing diagnostic protocols and disease control and prevention regimens. The objectives of this study were to determine the long-term effect of PCV2 infection, the effect of re-infection with a homologous PCV2 strain, and the effect of repeated infection with heterologous PCV2 strains on pathological, virological, serological, and clinical parameters.

\section{MATERIALS AND METHODS}

\subsection{Animals and housing}

Twenty-four, 21-day-old, colostrum-fed, crossbred, castrated male pigs were purchased from a herd known to be free of porcine reproductive and respiratory syndrome virus (PRRSV) and swine influenza virus (SIV) and seropositive for PCV2. The pigs were weaned at 3 weeks of age and transported to the research facility at Iowa State University in Ames, Iowa, USA. On the day of arrival, the pigs were randomly assigned to 1 of 4 groups. All animals were housed in $2 \mathrm{~m} \times 2.5 \mathrm{~m}$ pens in separate rooms each equipped with one nipple drinker and a self-feeder. All groups were fed a balanced, pelleted, complete feed ration free of animal proteins and antibiotics (Nature's Made, Heartland Coop, IA, USA) ad libitum. Two randomly selected pigs (the pigs with the lowest identification numbers) from each group were tested and found to be negative for antibodies to porcine parvovirus (PPV), PRRSV, H1N1 SIV, H3N2 SIV, and Mycoplasma hyopneumoniae on arrival at the research facility at 3 weeks of age and at necropsy at 31 weeks of age.

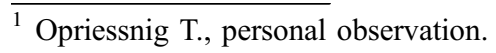


Table I. Experimental design.

\begin{tabular}{|c|c|c|c|c|c|}
\hline \multirow[t]{3}{*}{ Group designation } & \multicolumn{4}{|c|}{ Inoculation (weeks of age) } & \multirow{3}{*}{$\frac{\frac{\text { Necropsy }}{31}}{140 \mathrm{dpi}}$} \\
\hline & 11 & 16 & 21 & 26 & \\
\hline & $0 \mathrm{dpi}^{\mathrm{a}}$ & $35 \mathrm{dpi}$ & $70 \mathrm{dpi}$ & $105 \mathrm{dpi}$ & \\
\hline Negative controls $(n=6)$ & - & - & - & - & 6 pigs \\
\hline $\operatorname{PCV} 2 \mathrm{a}(n=6)$ & PCV $2 a^{b}$ & - & - & - & 6 pigs \\
\hline R-PCV2a $(n=6)$ & $\mathrm{PCV} 2 \mathrm{a}^{\mathrm{b}}$ & PCV $2 a^{b}$ & $\mathrm{PCV} 2 \mathrm{a}^{\mathrm{b}}$ & PCV2ab & 6 pigs \\
\hline R-PCV2a/b $(n=6)$ & PCV2a ${ }^{b}$ & PCV $2 b^{d}$ & $\mathrm{PCV} 2 \mathrm{a}^{\mathrm{c}}$ & PCV $2 b^{d}$ & 6 pigs \\
\hline
\end{tabular}

${ }^{\mathrm{a}}$ Days post inoculation (dpi).

${ }^{\mathrm{b}}$ Strain 40895.

${ }^{\mathrm{c}}$ Strain 4838.

${ }^{\mathrm{d}}$ Strain ADDLPP 10069.

\subsection{Experimental design}

The experimental protocol was approved by the Iowa State University Institutional Animal Care and Use Committee (IACUC number 3-06-6083-S). The experimental design is summarized in Table I. Each pig in 3 of the 4 groups received PCV2 strain 40895 at 11 weeks of age (dpi 0). Six pigs (RPCV2a) were re-challenged with PCV2a strain 40895 at 35, 70, and 105 dpi. Each pig in the RPCV2a/b group alternatively received PCV2a (dpi 0 and 70) and PCV2b (dpi 35 and 105). The two PCV2a strains used were heterologous. Blood samples were collected on arrival, dpi $0,2,4,6,8,10$, 12,14 , and weekly thereafter until necropsy on dpi 140. All pigs were necropsied $140 \mathrm{dpi}$ at 31 weeks of age. The presence, level, and duration of PCV2 viral DNA and anti-PCV2-antibodies in serum samples were compared across groups. Presence and level of neutralizing PCV2-antibodies in all pigs were compared at $10,14,21,42,105,112$, and 140 dpi. In addition, the average scores of the overall PCV2associated lymphoid lesions and incidence of PCV2 antigen were compared at $140 \mathrm{dpi}$.

\subsection{PCV2 isolates and inoculation}

The virus inocula were produced by transfecting PK-15 cells with infectious PCV2 stock as previously described [34]. PCV2 strain 40895 (PCV2a) (GenBank accession number AF264042) was recovered from an Iowa farm in 1998 [11] and has been well characterized genetically [11] and in the SPF pig model [12-14, 32-35, 37-39]. PCV2a 40895 was administered at a dose of $10^{4.5} 50 \%$ tissue culture infectious dose $\left(\mathrm{TCID}_{50}\right)$ intramuscularly $(1 \mathrm{~mL})$ and intranasally $(2 \mathrm{~mL})$. Using two inoculation routes was done to ensure that all pigs became infected at the same time as previously described $[25,35]$.

PCV2b strain ADDLPP 10069 (GenBank accession number EU594437) was isolated from lung tissue homogenate obtained from a pig in Indiana suffering clinical PCVAD on a farm experiencing approximately 25\% mortality. PCV2b strain ADDLPP 10069 was administered at a dose of $10^{4.5} \mathrm{TCID}_{50}$ intramuscularly $(1 \mathrm{~mL})$ and intranasally $(2 \mathrm{~mL})$.

PCV2a isolate 4838 (GenBank accession number DQ397521) was recovered from a subclinicallyinfected pig on an Iowa farm in 2003 [34]. PCV2a strain 4838 was given at a dose of $0.5 \times 10^{3.5}$ TCID $_{50}$ intramuscularly $(2 \mathrm{~mL})$ and intranasally $(2 \mathrm{~mL})$. The lower dose of the PCV2a 4838 inoculum was due to difficulty in growing the virus to a high titer in vitro.

\subsection{Clinical evaluation}

Following PCV2-inoculation, the pigs were evaluated daily for clinical signs including but not limited to wasting, lethargy, and anorexia.

\subsection{Diagnostic assays}

\subsubsection{Anti-PCV2-IgM-antibodies}

Serum samples were tested by a commercially available PCV2 ELISA IgM assay (Ingenasa, Madrid, Spain) with results expressed as optical density (O.D.) at $450 \mathrm{~nm}$. At this wavelength, the positive had to produce an O.D. of at least 0.7 Individual plate cutoffs were determined by multiplying the average O.D. value of the positive control well by 0.4 as recommended by the manufacturer. 


\subsubsection{Anti-PCV2-IgG-antibodies}

An in-house ORF2-PCV2 IgG ELISA was prepared and used as previously described [31]. Samples were considered positive if the calculated sample-topositive $(\mathrm{S} / \mathrm{P})$ ratio was 0.2 or greater. Previously, this ELISA has shown to have a sensitivity and specificity of $100 \%$ at the $\mathrm{S} / \mathrm{P}$ ratio 0.2 cutoff using samples from experimentally infected pigs on trial day 49 [41].

\subsubsection{PCV2 neutralizing antibodies}

A fluorescence focus neutralization assay was done on serum samples collected on 10, 14, 21, 42, 105,112 , and 140 dpi to determine the presence of neutralizing antibodies against PCV2 according to the Iowa State University Veterinary Diagnostic Laboratory standard operating protocol [42]. The assay was performed with PCV2a isolate ISU-98-15237.

\subsubsection{Additional serology}

The serum samples from 2 randomly selected pigs in each group taken on arrival at the research facility and at necropsy were tested for the presence of antibodies to PRRSV by PRRSV-ELISA (IDEXX Laboratories, Inc. Westbrook, MA, USA), PPV by hemagglutination inhibition (HI) assay [30], M. hyopneumoniae by ELISA [3], and H1N1 SIV and H3N2 SIV by HI assays according to the protocols used at the Veterinary Diagnostic Laboratory at Iowa State University.

\subsubsection{PCV2 DNA quantification}

DNA-extraction was done on $200 \mu \mathrm{L}$ of the serum samples collected on dpi $0,2,4,6,8,14$ and weekly thereafter until $140 \mathrm{dpi}$ was performed using the QIAamp ${ }^{\circledR}$ DNA Mini Kit (Qiagen, Valencia, CA, USA). DNA-extracts were used for quantification of PCV2 genomic DNA copy numbers by real-time PCR [32]. A sample with no threshold cycle $\left(C_{\mathrm{T}}\right)$ reading during the 40 amplification cycles was considered to be negative.

\subsection{Differentiation of PCV2a and PCV2b DNA by a quantitative multiplex real-time PCR}

Serum samples obtained from all pigs in the RPCV2a and R-PCV2a/b groups at dpi 35, 70, 105, and 140 were tested for PCV2a and PCV2b DNA by a multiplex quantitative real-time PCR. In brief, a forward (5'-GCAGGGCCAGAATTCAACC-3') and a reverse primer $\left(5^{\prime}\right.$-GGCGGTGGACATGATG AGA-3'), a probe specific for PCV2a (5'-Cal Fluor Orange 560-GGGGACCAACAAAATCTCTATAC CCTTT-BHQ-3'), and probe specific for PCV2b (5'-Quasar 670-CTCAAACCCCCGCTCTGTGCC C-BHQ- $3^{\prime}$ ) were designed in the Capsid-coding region of PCV2. The multiplex real-time PCR reaction consisted of a total volume of $25 \mu \mathrm{L}$ containing $12.5 \mu \mathrm{L}$ of the commercially available master mix (TaqMan ${ }^{\circledR}$ Universal PCR master mix, PE Applied Biosystems), $5 \mu \mathrm{L}$ DNA, $0.4 \mu \mathrm{M}$ of each primer, and $0.2 \mu \mathrm{M}$ of each of the probes. The reactions were carried out in a 7500 Fast Real-Time PCR system (ABI, Foster City, CA, USA) under the following conditions: $50{ }^{\circ} \mathrm{C}$ for $2 \mathrm{~min}, 95{ }^{\circ} \mathrm{C}$ for $10 \mathrm{~min}$, followed by 40 cycles of $95{ }^{\circ} \mathrm{C}$ for $15 \mathrm{~s}$ and $60{ }^{\circ} \mathrm{C}$ for $1 \mathrm{~min}$. The sensitivity and specificity of the real-time PCR reaction was evaluated by using known PCV2a and PCV2b isolates as well as PPV, PRRSV, and PCV type 1 (PCV1) isolates.

\subsection{Necropsy}

Necropsies were performed on all pigs at $140 \mathrm{dpi}$. The total amount of macroscopic lung lesions ranging from 0 to $100 \%$ of the lung affected and the size of lymph nodes ranging from 0 (normal) to 3 (four times the normal size) were estimated in a blinded fashion [38]. Lungs were insufflated with fixative. Sections of lymph nodes (superficial inguinal, mediastinal, tracheobronchial, mesenteric), tonsil, thymus, ileum, kidney, colon, spleen, and liver were collected at necropsy and fixed in 10\% neutral-buffered formalin and routinely processed for histological examination.

\subsection{Histopathology}

Microscopic lesions were evaluated in a blinded fashion by two veterinary pathologists (TO, PGH). Lung sections were scored for the presence and severity of interstitial pneumonia using the following scores: 0 (normal), 1 (mild focal), 2 (mild diffuse), 3 (moderate focal), 4 (moderate diffuse), 5 (severe focal) and 6 (severe diffuse). Sections of heart, liver, kidney, brain, ileum, and colon were evaluated for the presence of lymphohistiocytic inflammation and scored from 0 (none) to 3 (severe). Lymphoid tissues including lymph nodes, tonsil, and spleen were evaluated for the presence of lymphoid depletion ranging from 0 (normal) to 3 (severe) and histiocytic inflammation and replacement of follicles ranging from 0 (normal) to 3 (severe) [33]. 


\subsection{Immunohistochemistry (IHC)}

IHC for detection of PCV2-specific antigen was performed on selected formalin-fixed and paraffinembedded sections of lymph nodes (superficial inguinal, mediastinal, tracheobronchial, and mesenteric), tonsil, spleen, Peyer's patches, and thymus using a rabbit polyclonal antiserum [44]. PCV2-antigen scoring was done in a blinded fashion and scores ranged from 0 (no signal) to 3 (more than $50 \%$ of the $1 y m$ phoid follicles contain cells with PCV2-antigen staining) [33].

\subsection{Sequencing}

PCR products amplified from virus recovered from one randomly selected pig at $140 \mathrm{dpi}$ from each inoculation group were sequenced and compared to the respective original inoculum. Nested PCR was used to amplify the entire ORF2 gene for sequencing and subsequent sequence comparison [34]. The PCR products were run on a $1 \%$ agarose gel and the expected $820 \mathrm{bp}$ products were excised, purified and sequenced at the Iowa State University Sequencing facility. The sequences were analyzed and compared to the sequences of the original virus inocula.

\subsection{Statistical analysis}

Summary statistics were calculated for all groups to assess the overall quality of the data, including normality. Continuous repeated measured data (antibody levels, viremia) were assessed with the multivariate analysis of variance method (MANOVA). If the group by time interaction was significant $(p<0.05)$ the cross-sectional analysis was used to determine the significant time points [21]. Analysis of variance (ANOVA) was used for cross-sectional assessment of continuous measures. The rejection level for the null hypothesis was 0.05 followed by pairwise testing using the Tukey-Kramer adjustment. The severity of non-repeated measures of necropsy and histopathology data were assessed using non-parametric KruskalWallis one-way ANOVA. If this was significant $(p<0.05)$, then pairwise Wilcoxon test was used to assess differences between groups. Differences in incidence of macroscopic and microscopic lesions were evaluated by using Fisher's exact test. The Pearson product-moment correlation coefficient was used to determine the relation between neutralizing anti-PCV2 antibody levels and PCV2 DNA levels. Statistical analysis was performed using JMP software $\left(\mathrm{JMP}^{\circledR}\right.$ version 6.0.0, SAS Institute Inc., Cary, NC, USA).

\section{RESULTS}

\subsection{Clinical disease}

Clinical disease was not observed in any of the pigs. All pigs remained clinically healthy until termination of the study.

\subsection{Anti-PCV2 antibody responses over time}

The mean anti-PCV2 IgM responses in each group are summarized in Figure 1. The prevalence of anti-PCV2 IgM antibodies was as follows: 4/6 PCV2 pigs, 2/6 R-PCV2a pigs and 2/ $6 \mathrm{R}-\mathrm{PCV} 2 \mathrm{a} / \mathrm{b}$ pig were positive at $12 \mathrm{dpi}, 5 / 6$ PCV2, R-PCV2a R-PCV2a/b pig were positive at $14 \mathrm{dpi}, 3 / 6$ PCV2 pigs, 6/6 R-PCV2a pigs and $2 / 6 \mathrm{R}-\mathrm{PCV} 2 \mathrm{a} / \mathrm{b}$ pig were positive at $21 \mathrm{dpi}$, and 2/6 R-PCV2a/b pigs were positive at $28 \mathrm{dpi}$. There was a significant $(p<0.05)$ time by group interaction when the mean group O.D. values were analyzed; however, this was not the case when only the PCV2 inoculated groups were analyzed. The mean O.D. levels were significantly increased at $10 \mathrm{dpi}(p=0.03 ; \mathrm{R}-\mathrm{PCV} 2 \mathrm{a} /$ b pigs versus controls), $12 \mathrm{dpi}(p=0.03$; $\mathrm{R}-\mathrm{PCV} 2 \mathrm{a} / \mathrm{b}$ and PCV2a pigs versus controls), 14 dpi, 21 dpi, 28 dpi, 35 dpi (all: $p<0.01$; PCV2 inoculated groups versus controls), $42 \mathrm{dpi}$ $(p=0.01$; R-PCV2a and R-PCV2a/b pigs versus controls), $48 \mathrm{dpi}$ and $56 \mathrm{dpi}$ (both: $p=0.03$; R-PCV2a pigs versus controls). In the later stages of the study, the infection with homologous or heterologous PCV2 isolates did not affect the serum anti-PCV2 IgM O.D. levels.

The mean anti-PCV2 IgG responses in each group are summarized in Figure 2. There was a significant $(p<0.05)$ time by group interaction when all groups were analyzed; however, this was not the case when only PCV2 inoculated groups were analyzed. Five of eighteen, 8 of 18,17 of 18 , and 18 of 18 PCV2-inoculated pigs had positive anti-PCV2-IgG $\mathrm{S} / \mathrm{P}$ ratios by $12,14,21$, and $28 \mathrm{dpi}$, respectively. By $14 \mathrm{dpi}$, mean group $\mathrm{S} / \mathrm{P}$ ratios were significantly $(p=0.018)$ different between control pigs and the R-PCV2a/b group. By $21 \mathrm{dpi}$, the group means of all inoculated groups were above the 0.2 ELISA cut-off (Fig. 2). All inoculated pigs remained seropositive until termination of 


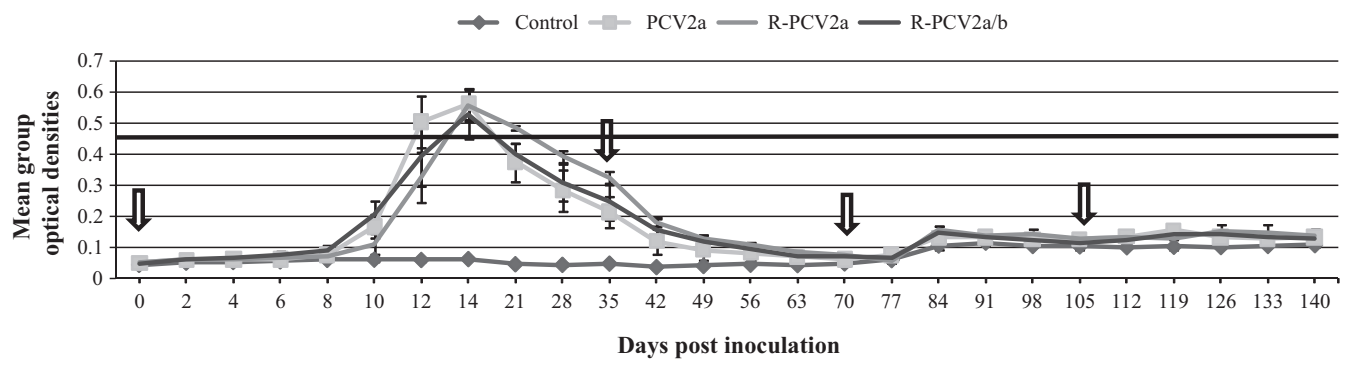

Figure 1. Mean group anti-PCV2 IgM response over time $( \pm \mathrm{SE})$. Arrows indicate the timing of PCV2 inoculation in groups PCV2a, R-PCV2a and R-PCV2a/b and reinoculation in groups R-PCV2a and $\mathrm{R}-\mathrm{PCV} 2 \mathrm{a} / \mathrm{b}$. The line indicates the average plate cutoff values. Individual plate cutoff values were determined by multiplying the average O.D. value of the positive control well by 0.4 as recommended by the manufacturer.

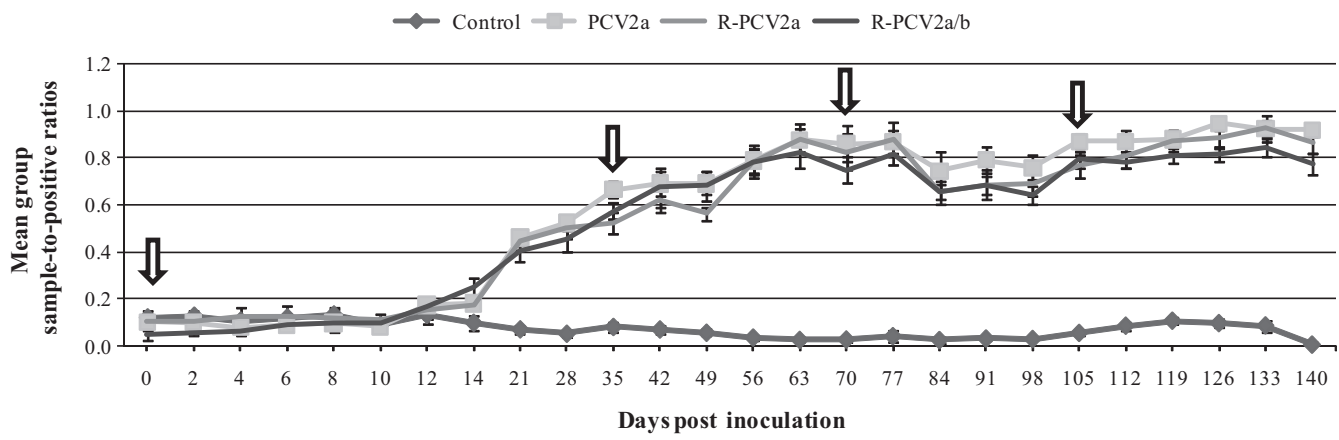

Figure 2. Mean group anti-PCV2 IgG response over time (measured by an ORF2-based ELISA assay) $( \pm \mathrm{SE})$. Arrows indicate the timing of PCV2 inoculation in groups PCV2a, R-PCV2a and R-PCV2a/b and reinoculation in groups $\mathrm{R}-\mathrm{PCV} 2 \mathrm{a}$ and $\mathrm{R}-\mathrm{PCV} 2 \mathrm{a} / \mathrm{b}$.

the study at $140 \mathrm{dpi}$ and had significantly $(p<0.001)$ higher mean group $\mathrm{S} / \mathrm{P}$ ratios compared to the control group. All negative control pigs remained negative throughout the study. From 21 dpi onwards, there were no statistically significant differences between PCV2inoculated groups regardless of re-infection with homologous or heterologous strains except for dpi 140 where PCV2a pigs had significantly $(p<0.01)$ higher mean $\mathrm{S} / \mathrm{P}$ ratios compared to the R-PCV2a/b group.

Log-transformed group mean anti-PCV2 neutralizing antibody levels are summarized in Figure 3. By $21 \mathrm{dpi}$, neutralizing antibodies were detectable and the mean group values were different from the negative control levels and remained significantly $(p<0.05)$ higher for the remainder of the study. There were no significant differences in neutralizing antibody levels among the PCV2-inoculated groups regardless of the infection status.

\subsection{PCV2 DNA loads in serum samples over time}

The group mean serum PCV2 DNA loads over time are summarized in Figure 4. There was a significant $(p<0.05)$ group by time interaction. Eight of 18 pigs inoculated with PCV2a were viremic by 2 dpi (Tab. II). 


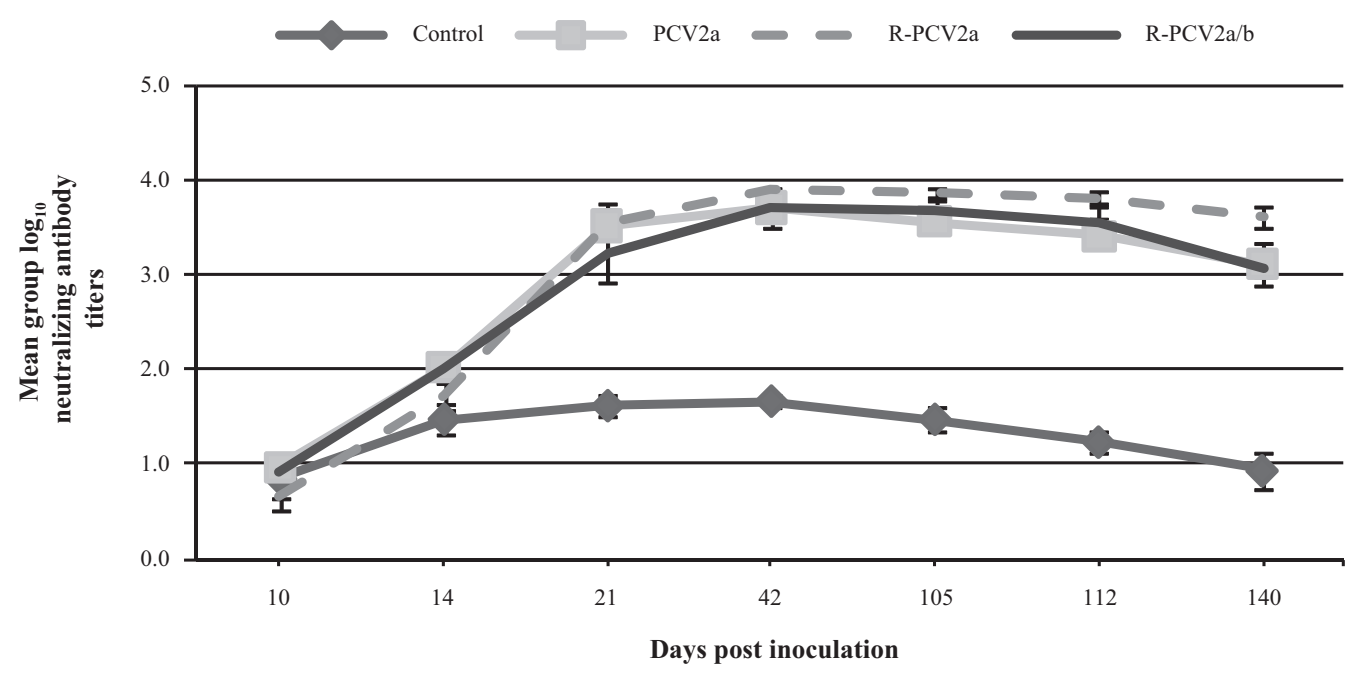

Figure 3. $\log _{10}$ transformed mean group neutralizing antibody response $( \pm \mathrm{SE})$. PCV2 inoculations were done on 0 dpi in the PCV2, R-PCV2a, and R-PCV2a/b groups and PCV2 reinoculations were done on 35, 70 , and 105 dpi in the R-PCV2a and R-PCV2a/b groups.

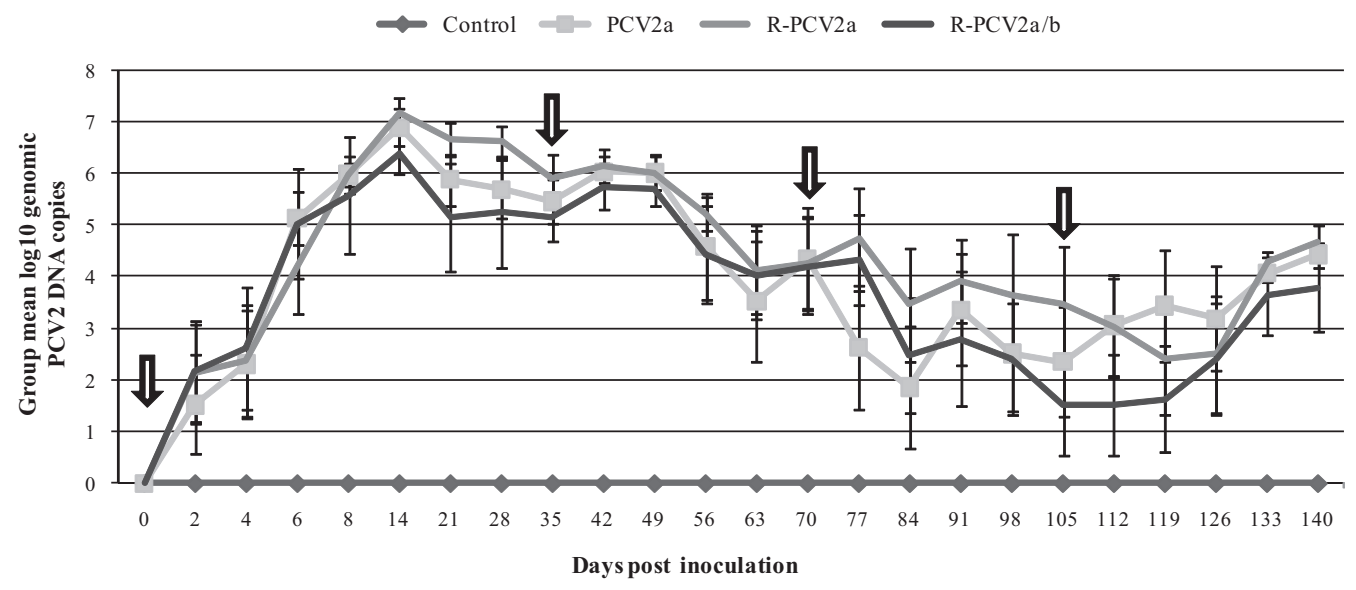

Figure 4. Mean group $\log _{10}$ PCV2 DNA levels over time $( \pm \mathrm{SE})$. Arrows indicate the timing of PCV2 inoculation in groups PCV2a, R-PCV2a and R-PCV2a/b and reinoculation in groups R-PCV2a and R-PCV2a/b. A sample with no threshold cycle $\left(C_{\mathrm{T}}\right)$ reading during the 40 amplification cycles was considered to be negative.

By 14 dpi, all 18 PCV2-inoculated pigs were PCV2 viremic. The amount of PCV2 DNA in serum in PCV2 inoculated groups was significantly different $(p<0.001)$ compared to control pigs starting on dpi 6 through dpi 77 and again on dpi 133 and 140. Individual pigs in all three PCV2 inoculated groups became negative for PCV2 DNA for up to seven consecutive bleeding days (Tab. II) but the majority of the pigs in all three groups remained viremic 
Table II. Presence $(+)$ or absence $(-)$ of PCV2 DNA as determined by real-time PCR on serum collected at different days post PCV2a inoculation. Reinoculation in groups R-PCV2a and R-PCV2a/b occurred on days 35,70 , and 105 .

\begin{tabular}{|c|c|c|c|c|c|c|c|c|c|c|c|c|c|c|c|c|c|c|c|c|c|c|c|c|}
\hline ig ID & 0 & 2 & 4 & 6 & 8 & 14 & 21 & 28 & 35 & 42 & 49 & 56 & 63 & 70 & 77 & 84 & 91 & 98 & 105 & 112 & 119 & 126 & 133 & 140 \\
\hline \multicolumn{25}{|c|}{ Controls } \\
\hline 1214 & - & - & - & - & - & - & - & - & - & - & - & - & - & - & - & - & - & - & - & - & - & - & - & - \\
\hline 1237 & - & - & - & - & - & - & - & - & - & - & - & - & - & - & - & - & - & - & - & - & - & - & - & - \\
\hline 1249 & - & - & - & - & - & - & - & - & - & - & - & - & - & - & - & - & - & - & - & - & - & - & - & - \\
\hline 1261 & - & - & - & - & - & - & - & - & - & - & - & - & - & - & - & - & - & - & - & - & - & - & - & - \\
\hline 1279 & - & - & - & - & - & - & - & - & - & - & - & - & - & - & - & - & - & - & - & - & - & - & - & - \\
\hline 1296 & - & - & - & - & - & - & - & - & - & - & - & - & - & - & - & - & - & - & - & - & - & - & - & - \\
\hline \multicolumn{25}{|c|}{ PCV2a } \\
\hline 1211 & - & - & - & + & + & + & + & + & + & + & + & + & + & + & + & - & + & - & + & + & + & + & - & - \\
\hline 213 & - & + & + & + & + & + & + & + & + & + & + & + & + & + & + & + & + & + & + & & & + & & + \\
\hline 1290 & - & - & + & + & + & + & + & + & + & + & + & + & + & + & + & + & + & + & + & & & + & + & + \\
\hline 1291 & - & - & - & + & + & + & + & + & + & + & + & - & - & + & - & - & + & + & - & - & . & - & + & + \\
\hline 1295 & - & - & - & + & + & + & + & + & + & + & + & + & + & + & - & - & - & - & - & - & + & + & - & - \\
\hline 1298 & - & + & + & + & + & + & + & + & + & + & + & + & - & - & - & - & - & - & - & + & - & - & - & + \\
\hline \multicolumn{25}{|c|}{ R-PCV2a } \\
\hline 1241 & - & + & + & + & + & + & + & + & + & + & + & + & + & + & + & + & + & + & + & + & + & + & + & + \\
\hline 1265 & - & - & - & - & + & + & + & + & + & + & + & + & + & + & + & + & + & + & + & + & - & - & + & + \\
\hline 1266 & - & - & - & + & + & + & + & + & + & + & + & + & + & + & + & + & + & + & - & + & + & + & + & + \\
\hline 1277 & - & + & + & + & + & + & + & + & + & + & + & + & - & - & - & - & + & - & - & - & - & - & + & + \\
\hline 1287 & - & + & - & + & + & + & + & + & + & + & + & + & + & + & + & - & - & - & + & - & - & - & - & - \\
\hline 1294 & - & - & + & + & + & + & + & + & + & + & + & + & + & + & + & + & + & + & + & + & + & + & + & + \\
\hline \multicolumn{25}{|c|}{ R-PCV2a/b } \\
\hline 1212 & - & - & - & + & + & + & - & - & + & + & + & - & - & - & - & - & - & + & - & - & - & + & - & + \\
\hline 1263 & - & + & - & + & + & + & + & + & + & + & + & + & + & + & + & + & + & + & + & - & + & - & + & + \\
\hline 272 & - & - & - & - & - & + & + & + & + & + & + & + & + & + & + & - & - & - & - & + & - & - & - & - \\
\hline 1275 & - & + & + & + & + & + & + & + & + & + & + & + & + & + & + & + & + & - & - & - & - & - & - & - \\
\hline 1293 & - & - & + & + & + & + & + & + & + & + & + & + & + & + & + & - & - & - & - & - & - & + & + & + \\
\hline 1297 & - & + & + & + & + & + & + & + & + & + & + & + & + & + & + & + & + & + & + & + & + & + & + & + \\
\hline
\end{tabular}

until the termination of the study at 140 dpi at which time the PCV2 DNA was detected in $13 / 18$ pigs in sera. There were no statistical differences $(p>0.05)$ in the level of PCV2 viremia in the three PCV2 inoculated groups; however, the mean group DNA amount in serum was also not different $(p>0.05)$ from the control pigs starting by dpi 84 until dpi 126. There was no increase in the amount of PCV2 DNA in sera after re-infection with homologous PCV2 (in the R-PCV2a group) or after challenge with a heterologous PCV2 strains (in the R-PCV2a/b group) compared to pigs singularly infected with PCV2a (Fig. 4).

Log-transformed PCV DNA levels and logtransformed neutralizing antibody levels had a correlation coefficient of 0.1368 on dpi 21 and 0.4012 on dpi 140 .

\subsection{PCV2 genotype present in the pigs}

PCV2b DNA was not detected in pigs from the R-PCV2a group on 35, 70, 105, and 140 dpi. In the R-PCV2a/b group, low levels of PCV2b DNA were detected in two pigs on dpi $140\left(1.3 \times 10^{4}\right.$ and $7.5 \times 10^{3}$ genomic cop$\mathrm{ies} / \mathrm{mL}$ serum, respectively) but not on any of the other days tested. Sequencing of the PCV2 ORF2 from one randomly selected pig in each of the PCV2-inoculated groups on dpi 140 confirmed the presence of PCV2a (100\% nucleotide sequence identity with PCV2 strain 40895). 


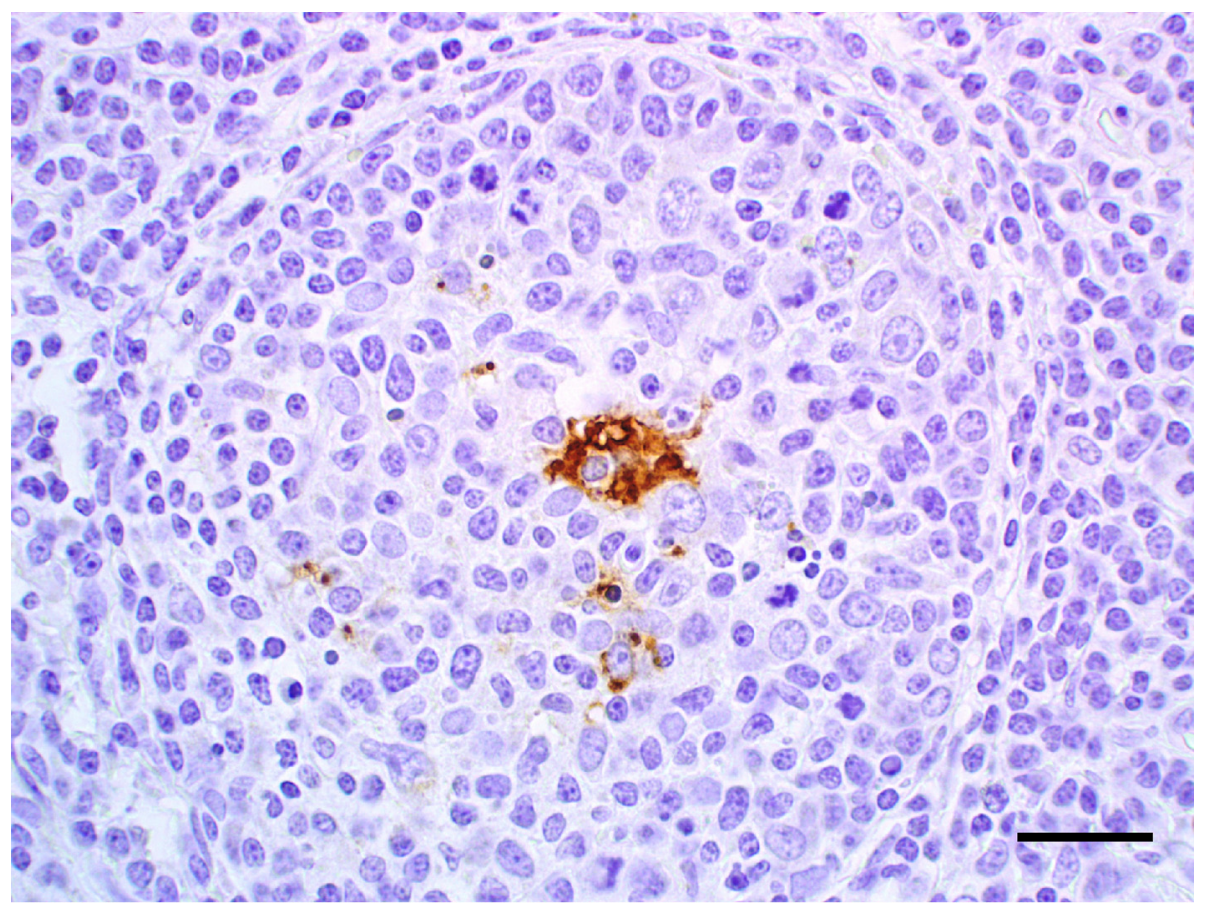

Figure 5. Lymph node, pig, inoculated with porcine circovirus type 2 (PCV2) 140 days previously. Immunohistochemical staining using a polyclonal antiserum against PCV2 revealing scant brown staining in the cytoplasm of macrophages-like cells in the center of lymphoid follicles. Streptavidin-biotinperoxidase complex method counterstained with hematoxylin. Bar $=40 \mu \mathrm{m}$. (A color version of this figure is available at www.vetres.org.)

\subsection{Macroscopic and microscopic lesions and the amount of PCV2 antigen in tissue samples collected at $140 \mathrm{dpi}$}

Macroscopic lesions were not observed in any of the pigs. Microscopically, 2/6 pigs in the PCV2a inoculated group and $1 / 6$ pig in the R-PCV2a group had mild lymphoid depletion, $1 / 6$ pigs (PCV2a) had moderate histiocytic replacement of follicles in lymphoid tissues, $1 / 6$ controls, 4/6 PCV2a, 4/6 R-PCV2a and 1/6 R$\mathrm{PCV} 2 \mathrm{a} / \mathrm{b}$ pigs had mild focal lymphohistiocytic hepatitis, and 3/6 R-PCV2a, 1/6 PCV2a and RPCV2a/b pigs had mild-to-moderate lymphohistiocytic interstitial nephritis. Mild interstitial pneumonia (score 1) was observed in $2 / 6$ PCV2a pigs, 3/6 R-PCV2a pigs, and 3/6 R$\mathrm{PCV} 2 \mathrm{a} / \mathrm{b}$ pigs. The incidence or severity of the lesions was not significantly $(p>0.05)$ different between groups.

Low amounts of PCV2 antigen was found in lymphoid tissues in $2 / 6$ PCV2a pigs (Fig. 5), 1/6 R-PCV2a pigs, and 2/6 RPCV2a/b pigs by using a PCV2-specific IHC method. There were no statistical differences $(p>0.05)$ in incidence of PCV2 antigen in tissues between groups.

\section{DISCUSSION}

Among 97 diagnostic submissions from field cases collected in the USA, PCV2a/b co-infection was demonstrated by PCR in $25 \%$ of the clinical samples [18]. We observed that PCV2 infection resulted in an anti-PCV2 IgM response 
followed by a strong anti-PCV2 IgG response in serum and a high prevalence of long-term PCV2 viremia. Individual PCV2 DNA-negative pigs were found throughout the study and some of those pigs (2/18) remained PCV2 DNA negative for up to 7 consecutive bleedings; however, at termination of the study, 13 of 18 PCV2 inoculated pigs were viremic. The observed intermittent PCV2 viremia pattern may be due to differences in replication kinetics, differences in replication sites, stressors, host susceptibility, or re-inoculation. Alternatively, it may be due to the detection limit of the PCR used. Samples were considered positive when the $C_{\mathrm{T}}$ value was less than 40. Samples were considered negative when there was no observed $C_{\mathrm{T}}$ value during the 40 amplification cycles. However, false positive results may arise due to overlap with background noise and accurate discrimination between positive and negative animals at high $C_{\mathrm{T}}$ values may not always be possible.

Persistent chronic infection is defined as establishment of equilibrium between the virus and the host's immune system, resulting in an infection of long duration. The present study demonstrated persistence of PCV2 through the 140 day observation period in conventional pigs. Previously, Bolin et al. [4] described detection of viremia for $125 \mathrm{dpi}$ in cesareanderived, colostrum-deprived pigs inoculated at 3 weeks of age. PCV2 was also successfully isolated from several tissues obtained from the pigs on $125 \mathrm{dpi}$. The authors concluded that the extended duration, after experimental inoculation with PCV2, and isolation of infectious virus from multiple tissues indicated the establishment of a persistent infection [4]. Likewise, in a study investigating persistence in sows with subsequent vertical transmission to piglets, PCV2 antigen was detected in lymphoid tissues, lungs, myocardium, and epithelial cells of the pinna of piglets born to sows inseminated with PCV2-spiked semen [26].

The predominate genotype of PCV2 identified in the group with repeated heterologous PCV2 challenges (R-PCV2a/b) was the PCV2a used for the initial infection. PCV2b was only detected in two pigs on the day of necropsy. This is similar to what has been previously described [38] and further confirms that PCV2 isolates are cross-protective and prior infection with PCV2a prevents or limits re-infection with a heterologous PCV2b strain. However, timing of concurrent or re-infection likely varies greatly in the field and may influence the development of viremia. In this study, re-infection occurred 5 weeks after the initial infection.

Although the anti-PCV2 antibodies present in the pigs were shown to have neutralizing capabilities, this was not correlated with a reduction of PCV2 viremia (correlation coefficient of 0.1368 on dpi 21 and 0.4012 on dpi 140). This is in contrast to what has been reported previously where neutralizing antibodies were found to be correlated with protection against replication and development of disease $[28,29]$. Gnotobiotic or SPF pigs with high levels of neutralizing antibodies did not have detectable PCV2 replication in inguinal lymph nodes. However, the differences in the pig source (gnotobiotics or SPF pigs versus conventional pigs), age of the pigs at inoculation (3 weeks of age versus 11 weeks of age), sampling protocols (lymph nodes biopsies versus serum), differences in the assays used to measure neutralizing antibodies, and study outcomes (clinically affected pigs versus healthy pigs) between the studies were considerable and directly comparing the results is problematic. In addition, while in the previous studies the pigs were monitored until dpi 21 [28, 29] when neutralizing anti-PCV2 antibodies just start to appear in serum, in the current experiment the pigs were monitored for 140 days post initial infection. Also, virus isolation titration on lymph nodes was used to determine presence of replicating PCV2 [28, 29]. In the current study, we determined the amount of PCV2 DNA in serum by quantitative real-time PCR. The PCR assay used [32] does not discriminate between viable and/or replicating PCV2 and non-viable PCV2 or DNA remnants. In addition, it needs to be considered that some of animals that were PCR positive had values close to the PCR cutoff and the biological significance of a low viremia level and the correlation with neutralizing antibody levels is unknown. However, PCV2 antigen was demonstrated by IHC in lymphoid tissues collected from pigs infected 140 days previously (Fig. 5). Others have 
estimated that a minimum viral load of $10^{8}$ PCV2 genomes per $500 \mathrm{ng}$ DNA is required in order to give visible IHC staining [5]. A high tissue level of PCV2 140 dpi despite the presence of high levels of anti-PCV2 IgG suggests that replicating PCV2 was still present locally. In addition, more recently Fort et al. [15] reported on co-existence of neutralizing antibodies and viral DNA in serum samples obtained from both clinically affected and non-affected pigs which reinforces that neutralizing antibodies alone are not sufficient for PCV2 clearance.

The results of the current study suggest that PCV2a and PCV2b co-infection administered 35 days apart is not sufficient to induce clinical disease in a conventional pig model. However, experimental infection of conventional SPF pigs with PCV2 results in persistent viral infection despite the presence of high levels of anti-PCV2-antibodies. A similar pattern was not only seen in re-infected animals but also in the PCV2a group which was inoculated only once 140 days prior to termination of the study.

All current commercially available PCV2 vaccines are killed products [36] and have been shown to reduce the level and length of PCV2 viremia in experimental models [16, 37, 39, 40] and under field conditions [10, 19, 23]. Reduction or elimination of PCV2 viremia after challenge was not observed in this study. Reasons for this may be that the initial viral infection results in persistence of the virus in cells of the immune system which may potentially interfere with antigen recognition or recall responses [22]. Killed vaccine products, on the other hand, apparently are sufficient to induce a protective sterilizing immune response against infections with live PCV2 when the vaccine is given prior to virus challenge. The efficacy of PCV2 vaccines in PCV2 persistently infected pigs is currently unknown and needs to be further investigated.

Acknowledgements. We thank Matt Boogerd for assistance with the animal work. Funding for this study was provided by the Iowa Healthy Livestock Initiative.

\section{REFERENCES}

[1] Allan G.M., Ellis J.A., Porcine circoviruses: a review, J. Vet. Diagn. Invest. (2000) 12:3-14.

[2] Allan G.M., Caprioli A., McNair I., LaganTregaskis P., Ellis J., Krakowka S., et al., Porcine circovirus 2 replication in colostrum-deprived piglets following experimental infection and immune stimulation using a modified live vaccine against porcine respiratory and reproductive syndrome virus, Zoonoses Public Health (2007) 54:214-222.

[3] Bereiter M., Young T.F., Joo H.S., Ross R.F., Evaluation of the ELISA and comparison to the complement fixation test and radial immunodiffusion enzyme assay for detection of antibodies against Mycoplasma hyopneumoniae in swine serum, Vet. Microbiol. (1990) 25:177-192.

[4] Bolin S.R., Stoffregen W.C., Nayar G.P., Hamel A.L., Postweaning multisystemic wasting syndrome induced after experimental inoculation of cesareanderived, colostrum-deprived piglets with type 2 porcine circovirus, J. Vet. Diagn. Invest. (2001) 13:185-194.

[5] Brunborg I.M., Moldal T., Jonassen C.M., Quantitation of porcine circovirus type 2 isolated from serum/plasma and tissue samples of healthy pigs and pigs with postweaning multisystemic wasting syndrome using a TaqMan-based real-time PCR, J. Virol. Methods (2004) 122:171-178.

[6] Caprioli A., McNeilly F., McNair I., LaganTregaskis P., Ellis J., Krakowka S., et al., PCR detection of porcine circovirus type 2 (PCV2) DNA in blood, tonsillar and faecal swabs from experimentally infected pigs, Res. Vet. Sci. (2006) 81:287-292.

[7] Cheung A.K., Lager K.M., Kohutyuk O.I., Vincent A.L., Henry S.C., Baker R.B., et al., Detection of two porcine circovirus type 2 genotypic groups in United States swine herds, Arch. Virol. (2007) 152:1035-1044.

[8] Cheung A.K., Homologous recombination within the capsid gene of porcine circovirus type 2 subgroup viruses via natural co-infection, Arch. Virol. (2009) 154:531-534.

[9] Dupont K., Nielsen E.O., Baekbo P., Larsen L.E., Genomic analysis of PCV2 isolates from Danish archives and a current PMWS case-control study supports a shift in genotypes with time, Vet. Microbiol. (2008) 128:56-64.

[10] Fachinger V., Bischoff R., Jedidia S.B., Saalmuller A., Elbers K., The effect of vaccination against porcine circovirus type 2 in pigs suffering from porcine respiratory disease complex, Vaccine (2008) 26:1488-1499. 
[11] Fenaux M., Halbur P.G., Gill M., Toth T.E., Meng X.J., Genetic characterization of type 2 porcine circovirus (PCV-2) from pigs with postweaning multisystemic wasting syndrome in different geographic regions of North America and development of a differential PCR-restriction fragment length polymorphism assay to detect and differentiate between infections with PCV-1 and PCV-2, J. Clin. Microbiol. (2000) 38:2494-2503.

[12] Fenaux M., Halbur P.G., Haqshenas G., Royer R., Thomas P., Nawagitgul P., et al., Cloned genomic DNA of type 2 porcine circovirus is infectious when injected directly into the liver and lymph nodes of pigs: characterization of clinical disease, virus distribution, and pathologic lesions, J. Virol. (2002) 76:541-551.

[13] Fenaux M., Opriessnig T., Halbur P.G., Meng X.J., Immunogenicity and pathogenicity of chimeric infectious DNA clones of pathogenic porcine circovirus type 2 (PCV2) and nonpathogenic PCV1 in weanling pigs, J. Virol. (2003) 77:11232-11243.

[14] Fenaux M., Opriessnig T., Halbur P.G., Xu Y., Potts B., Meng X.J., Detection and in vitro and in vivo characterization of porcine circovirus DNA from a porcine-derived commercial pepsin product, J. Gen. Virol. (2004) 85:3377-3382.

[15] Fort M., Olvera A., Sibila M., Segalés J., Mateu E., Detection of neutralizing antibodies in postweaning multisystemic wasting syndrome (PMWS)-affected and non-PMWS-affected pigs, Vet. Microbiol. (2007) 125:244-255.

[16] Fort M., Sibila M., Allepuz A., Mateu E., Roerink F., Segales J., Porcine circovirus type 2 (PCV2) vaccination of conventional pigs prevents viremia against PCV2 isolates of different genotypes and geographic origins, Vaccine (2008) 26:10631071 .

[17] Harms P.A., Sorden S.D., Halbur P.G., Bolin S.R., Lager K.M., Morozov I., Paul P.S., Experimental reproduction of severe disease in $\mathrm{CD} / \mathrm{CD}$ pigs concurrently infected with type 2 porcine circovirus and porcine reproductive and respiratory syndrome virus, Vet. Pathol. (2001) 38:528-539.

[18] Hesse R., Kerrigan M., Rowland R.R., Evidence for recombination between PCV2a and PCV2b in the field, Virus Res. (2008) 132:201-207.

[19] Horlen K.P., Dritz S.S., Nietfeld J.C., Henry S.C., Hesse R.A., Oberst R., et al., A field evaluation of mortality rate and growth performance in pigs vaccinated against porcine circovirus type 2 , J. Am. Vet. Med. Assoc. (2008) 232:906-912.

[20] Jacobsen B., Krueger L., Seeliger F., Bruegmann M., Segales J., Baumgaertner W., Retrospective study on the occurrence of porcine circovirus 2 infection and associated entities in Northern Germany, Vet. Microbiol. (2009) 138:27-33.

[21] James F.C., McCulloch C.E., Multivariate-analysis in ecology and systematic - Panacea or Pandora box, Annu. Rev. Ecol. Syst. (1990) 21:129-166.

[22] Kekarainen T., Montoya M., Mateu E., Segales J., Porcine circovirus type 2-induced interleukin-10 modulates recall antigen responses, J. Gen. Virol. (2008) 89:760-765.

[23] Kixmoller M., Ritzmann M., Eddicks M., Saalmuller A., Elbers K., Fachinger V., Reduction of PMWS-associated clinical signs and co-infections by vaccination against PCV2, Vaccine (2008) 26:34433451 .

[24] Larochelle R., Magar R., D'Allaire S., Comparative serologic and virologic study of commercial swine herds with and without postweaning multisystemic wasting syndrome, Can. J. Vet. Res. (2003) 67:114-120.

[25] Madson D.M., Ramamoorthy S., Kuster C., Pal N., Meng X.J., Halbur P.G., Opriessnig T., Characterization of shedding patterns of porcine circovirus types $2 \mathrm{a}$ and $2 \mathrm{~b}$ in experimentally inoculated mature boars, J. Vet. Diagn. Invest. (2008) 20:725-734.

[26] Madson D.M., Patterson A.R., Ramamoorthy S., Pal N., Meng X.J., Opriessnig T., Reproductive failure experimentally induced in sows via artificial insemination with semen spiked with porcine circovirus type 2, Vet. Pathol. (2009) 46:707-716.

[27] Magar R., Müller P., Larochelle R., Retrospective serological survey of antibodies to porcine circovirus type 1 and type 2, Can. J. Vet. Res. (2000) 64:184-186.

[28] Meerts P., Van Gucht S., Cox E., Vandebosch A., Nauwynck H.J., Correlation between type of adaptive immune response against porcine circovirus type 2 and level of virus replication, Viral. Immunol. (2005) 18:333-341.

[29] Meerts P., Misinzo G., Lefebvre D., Nielsen J., Bøtner A., Kristensen C.S., Nauwynck H.J., Correlation between the presence of neutralizing antibodies against porcine circovirus 2 (PCV2) and protection against replication of the virus and development of PCV2-associated disease, BMC Vet. Res. (2006) 30:6.

[30] Mengeling W.L., Ridpath J.F., Vorwald A.C., Size and antigenic comparisons among the structural proteins of selected autonomous parvoviruses, J. Gen. Virol. (1988) 69:825-837.

[31] Nawagitgul P., Harms P.A., Morozov I., Thacker B.J., Sorden S.D., Lekcharoensuk C., Paul P.S., Modified indirect porcine circovirus (PCV) type 
2-based and recombinant capsid protein (ORF2)-based enzyme-linked immunosorbent assays for detection of antibodies to PCV, Clin. Diagn. Lab. Immunol. (2002) $9: 33-40$

[32] Opriessnig T., Yu S., Gallup J.M., Evans R.B., Fenaux M., Pallares F., et al., Effect of vaccination with selective bacterins on conventional pigs infected with type 2 porcine circovirus, Vet. Pathol. (2003) 40:521-529.

[33] Opriessnig T., Thacker E.L., Yu S., Fenaux M., Meng X.J., Halbur P.G., Experimental reproduction of postweaning multisystemic wasting syndrome in pigs by dual infection with Mycoplasma hyopneumoniae and porcine circovirus type 2, Vet. Pathol. (2004) 41:624-640.

[34] Opriessnig T., McKeown N.E., Zhou E.M., Meng X.J., Halbur P.G., Genetic and experimental comparison of porcine circovirus type 2 (PCV2) isolates from cases with and without PCV2-associated lesions provides evidence for differences in virulence, J. Gen. Virol. (2006) 87:2923-2932.

[35] Opriessnig T., Fenaux M., Thomas P., Hoogland M.J., Rothschild M.F., Meng X.J., Halbur P.G., Evidence of breed-dependent differences in susceptibility to porcine circovirus type-2-associated disease and lesions, Vet. Pathol. (2006) 43:281-293.

[36] Opriessnig T., Meng X.J., Halbur P.G., Porcine circovirus Type 2 associated disease: update on current terminology, clinical manifestations, pathogenesis, diagnosis, and intervention strategies, J. Vet. Diagn. Invest. (2007) 19:591-615.

[37] Opriessnig T., Madson D.M., Prickett J.R., Kuhar D., Lunney J.K., Elsener J., Halbur P.G., Effect of porcine circovirus type 2 (PCV2) vaccination on porcine reproductive and respiratory syndrome virus (PRRSV) and PCV2 coinfection, Vet. Microbiol. (2008) 131:103-114.

[38] Opriessnig T., Ramamoorthy S., Madson D.M., Patterson A.R., Pal N., Carman S., et al., Differences in virulence among porcine circovirus type 2 isolates are unrelated to cluster type $2 \mathrm{a}$ or $2 \mathrm{~b}$ and prior infection provides heterologous protection, J. Gen. Virol. (2008) 89:2482-2491.

[39] Opriessnig T., Patterson A.R., Elsener J., Meng X.J., Halbur P.G., Influence of maternal antibodies on efficacy of porcine circovirus type 2 (PCV2) vaccina- tion to protect pigs from experimental infection with PCV2, Clin. Vaccine Immunol. (2008) 15:397-401.

[40] Opriessnig T., Patterson A.R., Madson D.M., Pal N., Halbur P.G., Comparison of efficacy of commercial one dose and two dose PCV2 vaccines using a mixed PRRSV-PCV2-SIV clinical infection model 2-3-months post vaccination, Vaccine (2009) 27: 1002-1007.

[41] Patterson A.R., Johnson J., Ramamoorthy S., Meng X.J., Halbur P.G., Opriessnig T., Comparison of three enzyme-linked immunosorbent assays to detect porcine circovirus-2 (PCV-2)-specific antibodies after vaccination or inoculation of pigs with distinct PCV-1 or PCV-2 isolates, J. Vet. Diagn. Invest. (2008) 20:744-751.

[42] Pogranichnyy R.M., Yoon K.J., Harms P.A., Swenson S.L., Zimmerman J.J., Sorden S.D., Characterization of immune response of young pigs to porcine circovirus type 2 infection, Viral Immunol. (2000) 13:143-153.

[43] Shibata I., Okuda Y., Yazawa S., Ono M., Sasaki T., Itagaki M., et al., PCR detection of porcine circovirus type 2 DNA in whole blood, serum, oropharyngeal swab, nasal swab, and feces from experimentally infected pigs and field cases, J. Vet. Med. Sci. (2003) 65:405-408.

[44] Sorden S.D., Harms P.A., Nawagitgul P., Cavanaugh D., Paul P.S., Development of a polyclonalantibody-based immunohistochemical method for the detection of type 2 porcine circovirus in formalinfixed, paraffin-embedded tissue, J. Vet. Diagn. Invest. (1999) 11:528-530.

[45] Tischer I., Gelderblom H., Vettermann W., Koch M.A., A very small porcine virus with circular singlestranded DNA, Nature (1982) 295:64-66.

[46] Wellenberg G.J., Stockhofe-Zurwieden N., De Jong M.F., Boersma W.J., Elbers A.R., Excessive porcine circovirus type 2 antibody titres may trigger the development of porcine dermatitis and nephropathy syndrome: a case-control study, Vet. Microbiol. (2004) 99:203-214.

[47] Yu S., Opriessnig T., Kitikoon P., Nilubol D., Halbur P.G., Thacker E., Porcine circovirus type 2 (PCV2) distribution and replication in tissues and immune cells in early infected pigs, Vet. Immunol. Immunopathol. (2007) 115:261-272. 